\title{
DE MESSAGERIES MARITIMES
}

De Messageries Maritimes, de groọtste Fransche StoomvaartMaatschappij, is in den laatsten tijd, vooral in de Fransche vaktijdschriften, het onderwerp geweest van reel critiek.

Hoofdzakelijk kwam die hierop neer, dat de administratie en het personeel, zoowel als het materieel verouderd waren, dat de commercieele geest an de onderneming vreemd was, en dat de eigen scheepsbouwwerf van de Maatschappij te La Ciotat zeer duur en onvoordeelig werkte, een blok aan het been was, die een groot deel der winsten absorbeerde.

Dat het materieel verouderd was blijkt uit de volgende becijfering.

Volgens de balans over het jaar 1901 was de vloot als volgt samengesteld :

13 passagiersschepen samen 45905 tons van 36 tot 21 jaar

16 " 66901 " 20 " 11 "

13 " "70482" " $10 " 2 "$

3 vrachtbooten " 9228 " 40 " 32 "

10 " $34212 "$ " 20 " $13 "$

4 " $12510 "$ " 7 " 4 "

of 42 passagiersschepen metende 183288 tons

en 17 vrachtbooten " 55950 "

totral 59 schepen " 239238 "

De gemiddelde leeftijd van de ton is ruim 16 jaar hetgeen voor eene mail- en passagierslijn zeer hoog mag worden genoemd.

Om nu na te gaan of voldoende op de vlootwaarde is afgeschreven, nemen sommige critici den volgenden maatstaf aan.

De bouwprijs van de geheele vloot, heeft volgens de balans van 1901 bedragen 174.166.538.38 francs. Bij eene gemiddelde afschrijving van 5 pCt. per jaar zou in 16 jaar 80 pCt. of 139.333.231.70 francs afgeschreven moeten ziju. De balans geeft een totale afschrijping van 72.630676 .39 francs of 66.702 .555 .31 francs te weinig. Juister lijkt mij de volgende berekening. 
Bij eene afschrijving van $5 \mathrm{pCl}$. per jaar is na 20 jaar de geheele warde van hel schip afgeschreven. $\mathrm{Na}$ dien tijd behoudt het echter eene zekere minimum waarde bij verkoop aas sloopers welke op j pCt. van den constructieprijs kan worden angenouneu. $\mathrm{Na} 19$ jaar afschrijving van $5 \mathrm{pCt}$ is dus verdere reserve overbodig geworden.

Op deze wijze berekend is de gemiddelde ouderdom van de ton met betrekking tot de afschrijving 12.91 jaar en żou dus 5 pCt. $\times 12.91=64.55$ pCt. van den bouwprijs of 112.424 .500 francs moeten ziju afgeschreven dat is circa 39.800 .000 francs meer dan de balans aangeeft.

De bouwprijs per ton bedroeg gemiddeld 725 francs en de balanswaarde 424.40 francs ${ }^{1}$ ).

Ter vergelijking kunnen de volgende eijfers dienen ontleend aan het laatst verschenen verslag van de stoomvaaart Maatschappij Nederland.

De constructie-waarde per ton bedroeg $f 262$, de gemiddelde leeftijd voor de afschrijving 6.6 jaar. De boekwaarde per ton f 172 of rekening houdende met de extra reserve voor afschrijving f 153. Hieruit blijkt dat gemiddeld per jaar $6 \frac{3}{10}$ pCt. is afgeschreven.

Waar dus voor de Messageries Maritimes een cijfer van 5 pCt. is aangenounen, is dit zeker niet te hoog maar eerder te laag.

Iuderdaad mag men in den tegenwoordigen tijd met zijne voortdurend stijgende behoeften aan snelheid, comfort en luxe van het reizend publiek, niet meer annemen dat gedurende 19 jaar een mailboot aan de behoeften van het verkeer zal blijven beantwoorden.

De maatstaf van afsehrijving der Messageries Maritimes is feitelijk circa 3.2 pCt. per jaar geweest zoodat gerekend is op een diensttijd van 30 jaar voor eene mailboot.

Dat dit eene fout is geweest, waarvan de aandeelhouders thans de wrange vruchten plukken, bewijzen de maatregelen, die blijkens eene onlangs gehouden buitengewone algemeene vergadering van aasdeelhouders, noodzakelijk zijn gebleken.

1) De balanswaarde van de vloot der P. en O. was $f 110$ per ton of juist de helft van de balanswitarde bij de Messageries Maritimes, terwijl de Engelsche Maalschappij veel meer noderne schepen telt. 
De nieuwe voorzitter van den raad van bestuur, tevens Directeur der Maatschappij, de Heer André Lebon, oud-minister van Koophandel in Frankrijk, heeft blijkens zijne redevoering in die vergadering, ingezien dat krachtig moest worden ingegrepen om de maatschappij weer op vasten basis terug te brengen. De verouderde vloot moest vervangen worden door nieuwere schepen, en dit kon niet worden gedaan zonder dat de onvoldoende afschrijvingen werden erkend.

Het kapitaal werd dus gehalveerd, teruggebracht van 60 millioen tot 30 millioen francs. De vrijkomende 30 millioen francs zullen kunnen dienen om de kapitaal verliezen, die bij verkoop van oudere booten zulleu onstann, te dekken.

Volgens de bovenstaande berekening is er minstens een te kort van 39.800 .000 francs, zoodat zelfs door de halveering van het kapitaal de vloot nog voor een kleine 10 millioen francs te hoog op de balans zal komen te staan.

Indien echter voortaau de afschrijuingen verhoogd worden, extra reserves gevormd in gunstige jaren om in slechte tijden de afschrijving ten volle te loen plaats hebben, is het te verwachten dat na verloop van tijd dat extraverlies zal worden ingehaald. Maar dan dient ook te worden erkend, dat de halveering van het kapitaal alleen niet voldoende is ow den toestand geheel te zuiveren en zullen de eerstvolgende balansen zeer ruine afschrijvingen moeten aantoonen.

De gevolgen van de te geringe afschrijvingen hebben zich ook nog in andere opzichten laten gevoelen.

De Messageries Maritimes exploiteeren stoomvaartlijnen in een 5 tal verschilleude richtingen te weten:

10. Australie

2. China en Japan

3o. Zuid Afrika

410. Zuid Amerika

$5^{\circ}$. Middelandsche Zee.

Voor eerstgenoemde is de vereischte snelheid het grootst. De concurrentie van de naties onderling dwong telkens tot meer vaart, waardoor het type der schepen moest worden vergroot oin de zware machines en de groote voorraden steenkolen te kunnen bergen, Wij zien dan ouk dat de meest moderne schepen voor de Australie- en China-vaarten worden gebruikt. 
Schepen speciarl voor die vaart gebouwd, verouderden echter spoedig door de voortdurende toenerning der door het gouvernement vereischte snelheid en daar de afschrijvingen onvoldoende waren om zonder groot kapitaal verlies die schepen te verkoopen werden zij geplaatst op de kortere trajecten in de Middellandsche zee, waar minder suelheid werd vereischt.

Maar waren zij te langzaan geweest voor de groote mailvaart, zij liepen te snel voor de "Grand Cabotage", de groote kustvaart, hadden te veel laadruinte en te groote passagiers-inrichtingen, te zware machines en verbruikten veel te veel steenkolen. Zij waren wat men pleegt te noemen te klein voor een tafellaken en te groot voor een servet.

Iedere vaart heeft hare bijzondere eisehen. Het is de taak van den reeder om die nauwkeurig te bestudeeren en de schepen geheel in overeenstemming daarmede te houwen.

De hoeveelheid ladiug, het aantal passagiers $1^{\circ}$ en $2^{\theta}$ en $3^{\circ}$ klasse, de benoodigde sselheid zijn factoren die ieder afzonderlijk samenwerken om het type van schip voor eene speciale vaart samen te stelleu.

Wie een van deze factoren verwaarloost werkt op den duur met een ouvoordeelig schip en ziet zijne winsten verdwijnen, ow plaats te maken voor verlies.

Aan dit gevaar zijn de Messageries Maritimes niet ontsuapt en de oorspronkelijke fout van onvoldoende afschrijving heeft dus het dubbele bezwaar gehad van verouderde schepen op vaarten te moeten gebruiken warroor zij ongeschikt waren om ten slotte te moeten erkennen dat de helft van het kapitaal verloren is.

Daar de voorzitter der Maatschappij in de vergadering van aandeelhouders zoo duidelijk den toestand der Maatschappij uiteengezet heeft, geloof $i k$, dat het goed is een gedeelte van zijne toespraak in zijn geheel weer te geven.

Die heer zeide het volgende:

Men vraagt mij onophoudelijk waarom wij niet doen wat de Buitenlandsche Maatschappijen doen. Het zij mij vergund op dit teere punt niemand te noemen; ik respecteer onze concurrenten en ik wensch slechts op te merken, dat waar men nauwkeurig opsomt welke uitgaven de buitenlandsche maatschappijen zich getroosten, men niet in het.licht stelt 't geen zij ontvangeu. 
Neem ik de twee groote Duitsche Maatschappen gedurende de laatste 10 jaren - in den nacht der tijden ga ik dus niet terug - dan vind ik clat de eene gedurende 3 achtereenvolgende jaren geen cent dividend beeft nitgekeerd en de andere gedurende 6 jaren niets of uninder dan 4 pCt. heeft gegeven. De resultaten voor de andeelhouders der Messageries Maritimes zijn aanmerkelijk gunstiger geweest ${ }^{2}$ ).

Wend ik mij naar Engeland en ga ik daar de lijst der groote stoomvartlijnen na, die men ons wel telkens als model voor oogen wil houden, dan zie ik dat er meer dan eene is die geregeld $3,2,1 \frac{1}{2}$ p.Ct. of geen dividend uitkeert.

Andere geven ninder ongunstige resultaten.

Eén e maatschappij haalt men telkens aan - en niet zonder reden, - de Peninsular \& Oriental Steam Navigation Company, wier werkkring het meest met de onze overeenkomt en die geregeld booge divideuden nitkeert.

Ik vraag aan de regeering, aan de Fransche nijverheid en handel om de Messageries Maritimes in denzelfden toestand te brengen als de $P$. en $O$. De $P$. en $O$. met eene vloot van eenige duizenden tonuen grooter dan de onze, heeft een kapital van 40 millioen francs minder dan wij, tengevolge van het versehil in constructie prijs op Engelsche en Fransche werven. Dat verschil in kapitaal, dat zijp̣ invloed doet gevoelen in lagere afschrijvingen en rente, vind ik ook terug in de rekeningen van reparatio en onderhoud. De Engelsche werven toch repareeren goedkooper dan de Fransche werven, niet alleen dan onze eigen werven te La Ciotat, zooals men dat heeft willen laten voorkomen, maar goedkooper dan eenige Fransche werf zouder uitzondering.

Maar daar is meer. De Engelschen zijn niet belemmerd door bepalingen die overeenkomen met die voor onze "inscrits maritimes" die dateeren van den grooten Colbert. Indien de $\mathbf{P}$. en O. Lascars, Japanners of Chineezen wil gebruiken, dan kan

2) Bij nadere beschouwing van de laatst verschenen Balans van de Norddeutscher Lloyd de eenige Duitsche gesubsidieerde maildienst naar Oost-Azië en Australië, blijkt dat op die vaarten een verlies is geleden van circa 4 millioen mark dat betaald is uit de zeer ruime winsten in de ongesubsidieerde Amerika-vaart behaald, terwijl ten, slotte nog een dividend van $81 \mathrm{pCt}$. kon worden betaald. 
zij dat onbelemmerd doen. - Missohien zuinigt zij daarmede viet zooveel uit op gages, maar wel op voedingskosten. Een Furopeaan kost ons 2.50 francs per dag; een Lascar slechls 0.50 franes en over de geheele vloot makst dat alleen een verschil van 1.500.000 francs per jaar uit.

Wanneer wij désgelijks zullep mogen doen, dan zullen wij ook gelijke resultaten kunneu geven, maar ik moet er tegen opkomen, dat men toestanden vergelijkt die eenvoudig niets met elkander gemeen hebben, met miskenning văn de wonderen van vindingrijkheid, zuinigheid en werkzaamheid die wij noodzakelijk iederen dag moeten doen om den strijd vol te houden.

Daarua wijdt de heer Lebon uit over de verouderde administratie en het in den dienst vergrijsde personeel. De administratie roemt hij als uitstekend; het personeel acht hij in alle opzichten bekwaam, maar geeft toch toe, dat sommige zeer oude ambtenaren vervaugen zijn geworden, en dat de daardoor vrijgekomen salarissen zijn besteed voor $\frac{1}{3}$ als afstapperygeld aan de ontslagen beambten, voor $\frac{1}{3}$ aan hen die hunne werkzaamheden hebben overgenomen en voor $\frac{1}{3}$ tot besparing op algemeene onkosten.

Het verwijt van gebrek aan commercieele activiteit beantwoordt de heer Lebon als rolgt:

Men zegt ons: Misschien zijt gij zelve nog te verontschuldigen maar uwe agenten zijn niet aetief, zij zoeken niet naar uitbreiding van zaken.

Ik heb reden om te veronderstellen dat zij die zoo spreken zich over het algemeen weinig rekenschap geven van de groote veranderingen die het transport bedrijf heeft ondergaan.

In 30 jaren nadat het Suezkanaal werd geopend, is de vracht naar Oost Azie gedaald van gemiddeld 335 francs in 1872 tot 45 francs in 1901, maar desniettegenstaande zijn en blijven stoomvaartlijnen evenzeer als spoorwegen de meest impopulaire instellingen op aarde, omdat zij zoowel producenten als consuinenten tegen zich in het harnas vinden en op den duur geen reputatie hoe ook gesteund door ruime publiciteit, waaraan wij niet doen, tegen zulk eene combinatie bestand is.

Gij vraagt een ander voorbeeld? Geeft gij a rekenschap van de toenemende moeilijkbeden die de zaken met zich medebrengen zelfs in de laatste 15 jaren? Ons vrachtbureau te 
Marseille behandelt tegenwoordig het viervoudig aantal colli van 15 jaar geleden; het gewicht is slechts verdubbeld en de bruto ontvangsten zijn gelij! gebleven. Niet de netto ontvangvangsten, want de exploitatiekosten zijn belangrijk toegenomeu, zoodat het resultaat is dat wij met viermaal zooveel werk tegenwoordig slechts een gelijk bedrag an vracht inuen als 15 jaar geleden, terwijl de netto inkomsten belangrijk ziju gedaald.

De oorzaak hiervan Mijneheeren is te zoeken in toenemende concurrentie.

Vroeger waren wij en de P. O. de eenige maillijnen naar Oost Azie. Thans zijn er 4. De Duitschers en Japanners ziju er bijgekomen.

Wij waren de eenige Fransche maatschappij. Thans zijn er 2 audere die dezelfde havens bedienen als wij. Niettemin is er van achteruitgang bij ons geen sprake. Integendeel; passagiers- en goederenvervoer nemen op alle lijnen helangrijk toe en noch de buiteulandsche noch de Frausche clientele laat ons in den steek. Maar dezelfde inkomsten geven niet meer dezelfde winsten van vroeger.

Niettemin is het noodzakelijk om den ijver der agenten te prikkelen, want de concurrentie is verre van te verminderen. Daarom hebben wij de vaste salarissen der agenten met een derde verminderd met het verzoek door meerdere commissies dit verlies goed te maken.

De 4, grief tegen deze maatsohappij is gericht tegen de werkplaatsen van La Ciotat.

Ik geloof dat wij zeer voorzjchtig moeten zijn met hetgeen men ons daaromtrent verwijt, want de mogelijkheid is niet uitgesloten, dat zich achter die kritiek belangen verbergen die niets liever zouden zien dan sluiting der zaak waardoor andere werven de bedieuing van onze 8 millioen fraucs reparaties en 8 a 10 millioen francs voor nieuwen aanbouw in de constructie periode zouden kunnen krijgen.

Niettemin hebben wij een onpartijdig oordeel over dit onderdeel van onze zaak willen veruemen en hebben dus aan Le Creusot, de grootste industrieele instelling van Frankrijk gevraagd om door twee harer ingenieurs een onderzoek naar de toestand onzer werven te laten instellen. Dat rapport, dat ons voor 3.weken bereikte 
spreekt met den grontsten lof over ons personeel en de lage algemeene onkosteu.

Een aandeelhouder merkte zooeven op dat onze werktuigen verouderd zijn. Wij weten dat hij gelijk heeft en de planneu voor eene algeheele vernieuwing zijn gereed. Wij hebben dit niet eerder gedaan, ondat wij aan het einde waren van.eeu tijdvak van nieuwen aanbouw en dat een uitgaaf van én of anderhalf millioen voor nieuwe installaties niet gewettigd was, waar alleen de loopende reparaties in lhet vooruitzicht waren.

Maar wij hopen thaus met Uwe goedkeuring een nieuw programma voor de uitbreiding van onze vloot te gaan uitvoereu, en daarvoor zullen wij. de werven van la Ciotat geheel opnieuw uitrusten, niet slechts omdat daardoor sueller zal kunnen worden gebouwd, maar ook omdat eene aanzjenlijke jaarlijksche besparing zal worden verkregen.

$\mathrm{Na}$ dit vluchtige overzicht van de aanmerkingen die men op de Messageries Maritimes heeft gemaakt wensch ik de werkelijke redenen bloot te leggen die de tegenwoordige moeilijkheden. hebben veroorzaakt.

De oorzaak daarvan ligt in één toevallig feit en in verscheidene omstandigheden die niet toevallig zijn, waarvoor deze maatschappij niet verantwoordelijk kan worden gehouden, maar die niettemin een zeer nadeeligen iuvloed op den gang van zaken hebben gehạd.

Het toevallige feit is de kolencrisis, die ontstaan is juist na het sluiten van het nieuwe postcontract van 1894-95. Het is $\mathrm{I}$ bekend mijneheeren, dat deze overeenkomst gebaseerd is op den geuiddelden kolemprijs der daaraan voorafgaande jaren.

Nauwlijks echter was het nieuwe postcontract in werking getreden of de opwaartsche beweging der kolenprijzen begun, die ous in de 5 laatste boekjaren 1897-1901 een globaal verlies van 20 millioen francs heeft gegeven, waarvan 10 millioen

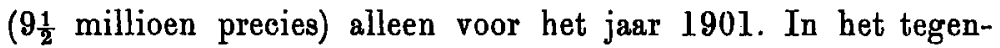
woordige boekjaar zullen wij eene kleine vermindering van die 10 millioen zien, zal het 2 of $2 \frac{1}{2}$ millioen zijn? maar in het gunstigste geval zullen wij nog 7 millioen meer uitgeven dan voorzien was in $1894-95$ en men behoeft geen rekenkunstenaar te zijn om de gevolgtrekking te makeu, dat met hetgeen thans in Amerika en Frankrijk voorvalt en hetgeen ons voorspeld 
wordt voor de maand Januari in Engeland, er niet de minste kins bestaat dat de prijzen tot het peil van 1893-4 terugvallen, althans gedurende het tijdvak dat ons scheidt van de beeindiging onzer postcontracten. Dientengevolge is er alle kans dat de postdienst voor ons eene geringe winst zal geven, zoolang wij op de tegenwoordige basis voortwerken.

Ook de vloeibare brandstof kan ons niet uit de moeielijkheid helpeu, want hoewel technisch de zaak volkomen is voorbereid, bestaat ointrent de levering van de brandstof zelve niet voldoende zekerheid om de willioenen dit de wijziging onzer ketels van kolen tot olie als brandstof zouden kosten, uit te geven.

In het najaar van 1900 hebben wij een beroep gedaan op het gouvernement om ons in de aanhoudende kolencrisis tegemuet te komen.

De Minister heeft geantwoord dat de risico daarvan geheel voor onze rekening was, dat hij er niets mede te maken had en dat de crisis reeds teu einde liep. Dat was in 1900; in 1901 was de crisis nog grooter geworden en in 1902 is zij nog altijd heviger dan in 1900 toen de Minister meende dat zij reeds ten einde liep.

De vrijheid ow het contract op te zeggen zooals een aandeelhouder ons aangeraden heeft, hebben wij niet. Het contract met de regeering is poor een zeker aantal jaren gesloteu en wij moeten dat coutract ten einde toe uitvoeren onder welke omstandigheden ook.

Voor eene enkele lijn konden wij het contract opzeggen en wij hebben het gedaan.

Maar een en ander heeft ons het besluit doen nemen om. geen groote uitgaven meer te doen om persouen te gerieven, die ous zoo welwillend naar de risico's van het bedrijf verwijzen; wij zullen in het vervolg uitsluitend ons eigen belang in het oog houden zooveel te meer omdat, wat ons betreft, de kolencrisis nog verscherpt werd door bijkomende omstandigheden die geenszins toevallig zijn maar waarvan de verautwoordelijkheid geheel op de schouders van den Staat zelve rust.

Ik doel hier op de slechte gewoonte van de schatkist om ons doorloopend eene som vau 5 à 6 millioen francs voor achterstallige vracht en passage schuldig te zijn, en die millioenen moeteu wij ons dan tijdelijk door bankiers verschaffen die zoo- 
als allen weten die wel eeus met bankiers te maken hebben gehad, niet om niet dergelijke sommen voorschieten.

Daar zijn nog andere zeer eigenaardige gebruiken bij het Gouvernement.

Het is $\mathfrak{u}$ bekend dat de staat rolgens ons contract eene reductie van $30 \mathrm{pCt}$. geniet op de vracht en passagegelden.

Maar nauwlijks was de overeenkomst gesloten of met dezen en genen vrachtspeculant wordt eene enkele bevrachting voor 50 pCt. reductie afgesloten, waarvan de staat gebruik maakt om ons voor de keus te stellen de clientele te verliezen of eveneens 50 pCt. reductie te geven.

Maar dit is nog niet alles. Men is gewoon om veel waarde te hechten aan het postsubsidie en met voorliefde beticht men de "bevoorrechte maatschappijen" van mishandeling vau het weerlooze publiek.

Laat mij hierop antwoorden dat de subsidie bepaald wordt door twee factoren.

In de eerste plaats door den prijs van de brandstoffen. Voor den postdienst wordt eene snelheid vereischt die allerminst overeenkomt met eene commercieele snelheid, en men is verplicht mailbooten te bouwen die op zichzelf beschouwd slechts met verlies te exploiteeren zijn, wegens de geringe ruimte voor lading, waarvan bij gelijke capaciteit de bouwprijs het dubbele bedraagt en die 2 maal zooveel steenkolen verstoken. De subsidie moet dit element van comınercieele minderwaardigheid uitwisschen en sedert de verhooging der steenkolenprijzen is dit allerminst het geval.

Maar ook dit is nog niet alles. De overeenkomsten met den staat bevatten bepalingen die ons dwingen op een tevoren vastgesteld uur te vertrekkeu, zoodat wanneer eene werkstaking te Marseille ons belet lading in te nemen, wij ledig moeten vertrekken.

Eene andere bepaling schrijft ous voor ook in tusschenhavens op een vast uur te vertrekken, en bij vertraging eene boete te betalen: maar als die vertraging veroorzaakt wordt door eene commercieele operatie dan vervalt die boete? neen Mijne heeren dan wordt ze verdubbeld. Eene commercieele operatie eene vertraging om den handel te gerieven wordt tweemaal zoo zwaar gestraft als een fout van den gezagvoerder. 
En dan verbaast men zich soms nog dat wij goederen achterlaten, terwijl de staat ons er toe noodzaakt door zijne opvattiug van de contracten. De vrijheid die de Engelsche mail heeft tusschen de punten van vertrek en aankomst missen wij, zoodat wij er slechter aan toe zijn dan onze Engelsche concurrenten en de vrije scheepvaart, waardoor het beoogde doel van de subsidie wordt gemist.

Maar ook dit is nog niet alles.

De conventie van 1894-95 werd gesloten onder de wet van 1893 op de handelsvloot, en op de basis der toen ter tijde bestaande premies op de vrije scheepvaart. De wet van 7 April jl. heeft plotseling die vroegere wet te niet gedaan en tengevolge gehad:

$1^{\circ}$ Dat voor de schepen gebouwd onder de wet van 1893 de prewie na 10 jaren dienst zal ophouden;

$2^{\circ}$ dat aan schepen die na 7 April 1902 in de vaart worden gebracht eene premie zal gegeven worden die 60 pCt. hooger is dan die van de wet van 1893 .

Daardoor is het tegeuwoordig voordeeliger geworden de vrije vrahtvaart uit te oefenen, tegen betaling der premies dan de postvaart tegen betaling van de subsidies.

Die vrije vrachtvaart is niets nieuws voor deze maatschappij. Reeds sedert lang hebben wij in navolging van andere maillijnen, getracht naast het postverkeer ook de vrachtvaart te ontwikkelen. Van de 900.000 mijlen die onze booten jaarlijks afleggen zijn slechts 520.000 mijlen op maildiensten. De andere zijn op commercieele vaarten; het is noodzakelijk ons in die richting uit te breiden.

De omstandigheden die $\mathrm{ik}$ a hiervoor heb uiteengezet brengen ons tot dezen stap, niet alleen om onze commercieele vaarten op gelijke hoogte te houden, maar ook om die uit te breiden en ons gaandeweg te voeren naar een standpunt waarop niet wij den Staat maar de Staat ous noodig zal hebben. Wanneer men iemand noodig heeft betaalt men hem op zijne juiste waarde.

Daarom moeten wij uitbreiding geven aan onze vrachtraart.

Tot zoover wat de heer Lebon gezegd heeft. Resumeerende is de indruk van deze redevoering wel deze dat de grieven tegen de Messageries Maritimes meerendeels zeer gegrond zijn geweest. 
De te oud geworden ambtenaren zijn vervangen door jongere krachten, die allicht ook in de administratie verandering en verbetering zullen brengen.

De werveu van La Ciotat zullen geheel nieuw met moderne machinerieën worden uitgerust en de vrijheid is verkregen om ook voor anderen sehepen te bouwen.

De vernieuwing van de vloot van vrachtbooten zal krachtig ter hand worden genomen, waardoor de eischen van den handel niet meer zoo geheel en al ondergeschikt zullen blijven aan de eischen van den Strat.

Merkwaardig steekt hierbij af de lange lijst van grieven die de heer Lebon - zelf oud minister van Koophandel - tegen de regeering opsomt.

Ruimte latende voor de meer en meer gebruikelijke wijze, die niet alleen speciaal Fransch is - om de moeilijkheden waarin men tijdelijk verkeert aan de regeering te wijten - wie herrinnert zich niet het vermakelijke spotlied van de Parijsche boulevards met het refrein - C'est la faute du Gouvernement! zijn de meegedeelde feiten op zich zelve voldoende om den indruk te vestigen dat de regeering hier niet geheel vrij te pleiten is van unbillijkbeid jegens de Messageries Maritimes.

Verbazingwekkend is de mededeeling omtrent de vrachtcontracten. Bij de postconventie wordt een passage- en vrachtovereenkomst gesloten waarbij het gouvernement $30 \mathrm{pCt}$ reductie op de particuliere tarieven zal genieten. Een onbevangen toeschouwer komt, dit reeds zeer hoog voor, maar de Staat scheen darmede nog niet tevreden te zijn en eischte op grond van eene tijdelijke depressie in de vrachtenmarkt, waardoor een in het nauw gedreven reeder eene enkele maal voor $50 \mathrm{pCt}$. reductie genegen was eene lading te vervoeren, diezelfde vermindering voor het geheele vervoer met de Maillijn.

Op zichzelf beschouwd is de methode waarhij de Staat van zijue groote macht als subsidiegever en groot vervoerder gebruik maakt om de maillijn te dwingen eene vaste belangrijke reductie op de particuliere tarieven toe te staan al in den grond vicieus. Want hij dwingt daarmede de reederij de particuliere tarieven zoo hoog mogelijk te houden teneinde niet de gouvernements goederen tot verliesgevende vrachten te vervoeren. En daarmede bereikt de Staat wel een tijdelijk direct finantieel voordeel, 
maar fnuikt reeds bij de geboorte den particulieren handel.

Subsidies worden thans aan reederijen gegeven in alle landen over de geheele wereld. Gedeeltelijk wordt daarmede beoogd eene postgemeenschap met eigen koloniën of andere landen waarvoor eene bijzondere snelheid wordt vereischt, die zonder subsidie niet. zou worden bereikt, en gedeeltelijk om onder eigen vlag de gemeenschap over zee te openen met landen waarmede geen voldoend verkeer is om zonder subsidie te kuunen varen.

In beide gevallen worden handel en nijverheid van het eigen land en de kolonien gesteund op eene wijze die voldoende blijkt uit den grooten vooruitgang die steeds is waar te nemen in deu handel met landen waarmede zulk een directe gemeenschap wordt geopend.

Maar dan moet een subsidie ook een subsidie blijven in den zin van eene uitkeering van den staat om eene anders verliesgevende vaart te onderhouden.

De Fransche regeering heeft er anders over gedacht. Met de eene hand gaf zij subsidie met de andere hand nam zij die in den vorm van reductie op de vracht terug. En de maatschappij die terwille van de postcontracten reeds eene vermindering van 30 pCt. had toegestaan, was kort daarop gedwongen 50 pCt. reductie te geven.

Hoe dit moet werken op den particulieren handel moet ieder duidelijk zijn die weet hoe belangrijk de factor van de vracht is in het internationale verkeer vooral bij goedkoope grondstoffen.

Eene regeering die zulke groote rrachtreducties eischt van de door baar gesubsidieerde reederij dwingt haar de particuliere tarieven hooger te stellen dan met de belangen van den handel is overeen te brengen en mist daardoor het doel dat zij zich met haar subsidie voor oogen stelde.

Het duidelijkst komt dit uit wanneer wij de quaestie zoo stellen.

Eene reederij heeft een zeker bedrag aan inkamsten noodig om exploitatiekosten, afschrijving en winst te dekken. Deze inkomsten worden verkregen door:

a. subsidie, b. vracht en passagegelden van het gouvernement en c. vracht en passagegelden van particulieren. 
a. is voor een zeker anntal jaren vastgesteld. Wordt $n u^{5} b$. sterk verlaagd dan zal c. zooveel meer moeten bedragen en daar de hoeveelheid daarvan niet naar willekeur kan worden vergroot zal de eenheidsprijs verhoogd moeten worden.

De verdere klachten tegen het gouvernement spruiten vocrt uit eene voor de maatschappij onvoordeelige overeenkomst. De verhooging van den steenkolenprijs was niet voorzien bij de sluiting van het 15 jarig conctract. Toen de verhooging zich uitbreidde tot de steenkolencrisis die wij in de afgeloopen jaren hebben gekend, was het eenerzijds te verwachten, dat de matschappij zou vragen om eenige tegemoetkoming, anderzijds te voorzien dat de regeering die zou weigeren. Maar de Messageries Maritimes zullen bij een volgend contract de mogelijkheid van eene herhaling der crisis in anmerking moeten nemen.

De gedwongen vertrekuren van tusschenliggende havens zijn onereus voor de maatschappij en het feit dat de Messageries Maritimes dergelijke voorschriften hebben annvaard in afwijking van eenig ander bestaand mailcontract, zou onverklaarbaar zijn als de opheldering niet te vinden ware in de rede van den heer Lebon zelve.

In 1894-95 toen het contract gesloten werd was de maatschappij aan handen en voeten gebonden aan de regeering. Zij kon er niet buiten, maar de regeering was niet afhankelijk van de maatschappij. "Laten wij zorgen dat aan het einde van deze periode niet wij de regeering, maar de regeering ons noodig heeft," zegt de heer Lebon.

De oplossing die hij vindt is uitbreiding van de vrachtraart waardoor relatief de maildiensten aan belangrijkheid zullen verliezen. De ontwikkeling van het verkeer in andere landen geeft hem gelijk. Ook daar ziet men in, dat het vervoer van passagiers en post met zijne steeds hooger gestelde eischen van suelheid, luxe en comfort op den duur geen voldoende winsten afwerpt, en dat de dividenden thans evengoed als voorheen te voorschijn moeten komen aiet uit de staatsruif maar uit het grootluik.

De slotsoin van de rede van den heer Lebon is wel deze. Wij hebben fouten begaan in het verledene mar wij bebben die ingezien en gaan moedig aan het werk om ze te verbeteren.

$\mathrm{W}_{\mathrm{ij}}$ wenden ons af van den Start wiens schijnbaar hooge 
subsidies geene vergoeding geven voor de groote offers die daardoor van ons worden geeischt en wij wenden ons tot den handel en de industrie die ons den bloei onzer maatschappij zullen weergeven; wij hebben uit het oog verloren dat zonder den steun van die beide de reederij zich niet kan ontwikkelen en dat de welwillendheid van den Staat gepaard gaat met eene vernietigende belemmering van de zoo noodige vrijheid van beweging.

Het is bekend dat de Nederlandsche mailvaart er steeds naar gestreefd heeft zich in die richting te ontwikkelen en $i k$ heb gemeend dat het voor het Nederlandsche publiek belang kon hebben te vernemen dat ook in Frankrijk deze inzichten bij de grootste gesubsidieerde stoomvaart Maatschappij ingang hebben gevonden.

Amsterdam, Dece in ber 1902. WaLante Borssevain. 